\title{
"DO HIGH-TECH À AZTECA": DESCOLONIZAÇÃO CRONOQUEER NA CIBERARTE CHICANA
}

\author{
Eliana de Souza Ávila \\ Universidade Federal de Santa Catarina
}

\begin{abstract}
Resumo: Este artigo contextualiza a arte chicana na concepção descolonial da região de Aztlán, confirmando claramente que "a América Latina não está inteiramente no território que leva este nome"'. Essa apropriação 'territorial' é também um deslocamento descolonial da temporalidade, pois expõe o regime crononormativo que relega epistemas não eurocêntricos ao passado. Especificamente, o artigo demonstra que a ciberarte chicana descoloniza a temporalidade ao recusar a versão pós-social ou transcendentalista da narrativa cyborg. Enfocando intervenções artísticas que desalinham ou 'queerizam' a prescrição crononormativa do passado como resíduo obsoleto de um futuro tecnológico triunfalista numa progressão linear, o artigo afirma uma concepção mais ampla, afrofuturista, da tecnologia (que reconhece o resíduo como seu suplemento constitutivo) enquanto ameaça efetiva à biopolítica crônica da crononormatividade.
\end{abstract}

Palavras-chave: arte descolonial; queer; crononormatividade; ciborgue; ciberarte chicana.

nós somos seu produto em certo sentido somos aqueles sobre quem você só pode sonhar detemos a artéria minúscula que faz seu link com o passado o cordão umbilical que te leva de volta às origens do Homo Punk ao Homo Pré-Hispânico do high-tech à azteca, sem perder compasso. Guillermo Gómez-Peña, "Border Brujo: A Performance Poem"

Longe de sugerir um retorno nostálgico ao passado, a expressão "do high-tech à azteca", que tomo emprestada do artivista Guillermo Gómez-Peña (1991), satiriza o discurso que consome o lado sul da fronteira dos Estados Unidos ao classificá-lo numa temporalidade essencialmente anterior à do norte, assim definida no presente. " "Border Brujo", performance da qual tomo emprestada a epígrafe acima, aconteceu perto das celebrações dos "500

Copyright @ 2015 by Revista Estudos Feministas.

1 Néstor García CANCLINI, 2008.

${ }^{2}$ Guillermo GÓMEZ-PEÑA, 1991, p. 53. A menos que esteja indicado nas referências bibliográficas, todas as traduções aqui são minhas. 
anos das Américas", quando se intensificou o questionamento do termo América Latina, por sua designação colonial e eurocêntrica. Desde os anos 1990, nesse contexto, difundiram-se mais amplamente tais autonomeações como Aztlán e Abya Yala, ${ }^{3}$ ressaltando a descolonização do continente e o fato de sua trajetória crítica direcionar-se justamente contra a identificação assimilacionista implícita na designação latina. ${ }^{4}$

Se os termos América e latina ignoram a atualidade de culturas heterogêneas no continente, em contrapartida eles também expõem a colonialidade do poder, "[...] a classificação social básica e universal da população do planeta em torno da idéia de 'raça' [...]" imbricada em hierarquias de gênero e sexualidade. ${ }^{5}$ Essa matriz classificatória se difunde como um curso natural ou correnteza evolutiva que por si só varre as/os outras/os da Europa como objetos e não sujeitos da história, do presente e do futuro. ${ }^{6}$ É nesse sentido que, para Nelson Maldonado-Torres, a colonialidade se perpetua como uma forma de poder que integra relações de conhecimento e mapeamento estabelecidas a priori entre um mundo marcado pela vida e outro pela patologia. ${ }^{7}$

A patologização torna as estruturas normativas imperceptíveis, naturalizadas em seu alinhamento com a narração do tempo de acordo com os modos de pertencimento constitutivos da colonialidade do poder, como um 'destino manifesto' refletindo a nação. ${ }^{8}$ Narrativas eugenistas e desenvolvimentistas são constitutivas dessa temporalidade (neo)colonial, de modo que saberes que abalam a crononormatividade são facilmente relegados ao passado. Com essa prescrição, a temporalidade fundada na perspectiva eurocêntrica do espaço das Américas e Caribe encobre a desqualificação e mesmo extinção de significados e formas de produção de conhecimentos que não se reduzem à configuração homogênea e crononormativa da colonialidade do saber. ${ }^{9}$ Nesse contexto, ir "do high-tech à azteca" só pode significar um retrocesso na medida em que se ignora o aparato colonial que ainda relega epistemas não crononormativos ao passado.

É no mínimo curioso que a pós-modernidade ocidental, supostamente libertando-se há pelo menos 50 anos de dicotomias essencialistas, consegue se vangloriar de sua imersão ciborguiana entre o presente e o futuro e, no mesmo ato, manter intacta sua dicotomia com o passado. Que as fronteiras geopolíticas da América Latina ao norte são também cronopolíticas

\footnotetext{
${ }^{3}$ Veja, por exemplo, Enrique DUSSEL, 1993a; Aijaz AHMAD, 2002; e Armando de Melo LISBOA, 2014.

${ }^{4}$ O termo Abya Ala foi inicialmente proposto em 1977 por Takir Mamani, diante do Conselho Mundial dos Povos Indígenas, para descentralizar a definição europeia do continente (LISBOA, 2014, p. 516), e significa "terra madura", contrapondo-se à crononormatividade. O termo é limitado, porém, resgatar a presença de significados indígenas mas não afrodescendentes (WALSH, 2007, p. 14). Sobre sua genealogia, veja Carlos Walter PORTOGONCCALVES, 2009 e LISBOA, 2014. Veja também o sítio do Centro Cultural Abya-Yala: www.abya-yala.org. ${ }^{5}$ Aníbal QUIJANO, 2002, p. 4. María LUGONES (2007) aponta para a imbricação mútua entre os sistemas de raça, gênero e sexualidade na constituição da colonialidade do poder. Sobre a exclusão de gênero e sexualidade em Quijano, ainda pouco comentada em discussões sobre sua concepção da colonialidade do poder, veja María LUGONES, 2007. Para um comentário elucidativo sobre essa exclusão, constitutiva da própria colonialidade do poder, veja Cláudia de Lima COSTA, 2010.

${ }^{6} \mathrm{Nesse}$ sentido, o termo confronta uma problemática similar à do terceiro mundo, que, ao mesmo tempo, reitera e expõe a essencialização identitária de regiões e populações objetificadas. Sobre a distinção entre categoria teórica e lócus de resistência, veja AHMAD, 2002.

${ }^{7}$ Nelson MALDONADO-TORRES, 2011 , p. 15.

${ }^{8}$ Essa crítica é elaborada, por exemplo, em Anne MCCLINTOCK, 1995; José Esteban MUÑOZ, 2009; e Judith HALBERSTAM, 2011.

${ }^{9}$ Walter MIGNOLO, 2003 [2000].
} 
é o problema, portanto, do qual surge este artigo. ${ }^{10}$ Especificamente, quero considerar como a arte chicana feminista intervém no fato de que as hierarquias que demarcam as divisas entre espaços demarcam também as fronteiras entre temporalidades avançadas e atrasadas, entre capacidades tecnológicas e fantasmáticas - e, crucialmente, entre quem pode e quem não pode narrar o futuro." Contra esse regime cronobiopolítico, algumas práticas artísticas engajam narrativas futuristas sobre a tecnologia de modos que parecem delinear uma percepção distinta - nem tecnofóbica nem tecnoeufórica- ou seja, partindo de um lugar de enunciação resistente aos posicionamentos dicotômicos ditados pela crononormatividade..$^{12} \mathrm{Nela}$, qualquer contranarrativa ao discurso tecnossalvacionista tende a ser desqualificada como anacrônica ou tecnofóbica. Este é o contexto discursivo que Gómez-Peña satiriza para sublinhar as expectativas frustradas de seu vizinho ao norte:

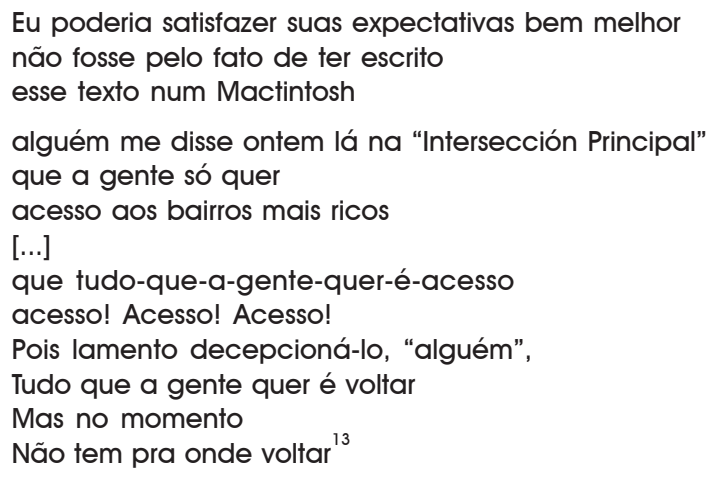

Aqui, a dinâmica monocêntrica da colonialidade do poder depende de ofuscar a atualidade das forças culturais heterogêneas participando assimetricamente - mas simultaneamente - de versões conflituosas da história. Com esse contexto em mente, enfocarei algumas intervenções artísticas que se situam nas fronteiras entre temporalidades ditas avançadas e atrasadas, fronteiras essas de onde outras percepções cronopolíticas vêm sendo articuladas na construção pós-identitária da América Latina.

\section{Aztlán, referência pós-ocidental}

As concepções contemporâneas de Aztlán (a palavra Nahuatl para o antigo território asteca) confirmam claramente que a "América Latina não está inteiramente no território que

\footnotetext{
${ }^{10}$ Refiro-me ao termo cronopolítica usado por Elizabeth FREEMAN para designar o dispositivo desenvolvimentista que "[...] permite à 'modernidade' ocidental [...] representar seu próprio avanço temporal em contraste com uma pré-modernidade temporalmente retardada, figurada como sendo de pele escura, feminina e eroticamente perversa". Esse dispositivo é ao mesmo tempo racializado, generificado e sexualizado, de modo que "[...] mecanismos de periodização em grande escala configuram o que pode ser vivido como uma formação social ou uma vida individual“" (FREEMAN, 2005, p. 57). Veja também MCCLINTOCK, 1995.

${ }^{11}$ Refiro-me ao conceito de narrar implícito no argumento de que "nenhuma fala é fala se não é ouvida", em Gayatri Chakravorty SPIVAK, 2005 [2000].

${ }^{12} \mathrm{~A}$ crononormatividade é "um modo de implantação, uma tecnologia cultural que dá aparência somática a forças institucionais", homogenizando as culturas "ao sincronizá-las em esquemas temporais compartilhados" na naturalização da heteronormatividade (Elizabeth FREEMAN, 2010, p. 3-4). Dessa desnaturalização emerge o signo queer, barrado da futuridade monopolizada pela reprodutividade heteronormativa (Lee EDELMAN, 2004). Em contraponto, o que é circunscrito ao passado revela justamente o que, por ser barrado do futuro, tem o potencial de mudá-lo (MUÑOZ, 2009).

13 GÓMEZ-PEÑA, 1991, p. 59-64
} 
leva este nome [...]". ${ }^{14}$ Designando a região da qual diversos povos vêm sendo expropriados sucessivamente (pelos astecas, pelos espanhóis, pelos EUA e pelo capital transnacional), Aztlán abrange o território extenso anexado pelos Estados Unidos por meio do tratado de Guadalupe-Hidalgo (1848): o centro e o noroeste do México, além dos estados do Novo México, Arizona, Texas, Califórnia, Nevada, Colorado e Utah nos Estados Unidos. ${ }^{15}$ Um território ao mesmo tempo mítico, utópico e histórico, descrito por Gómez-Peña como "flutuando / no éter / do tempo presente / da Califórnia / \& do tempo passado / do México", ${ }^{16}$ Aztlán é um dos lugares emblemáticos de enunciação da crítica latino-americana à colonialidade do poder, uma crítica ampla que se desenvolve bem antes da institucionalização da área acadêmica dos estudos pós-coloniais nos EUA dos anos 1980.17

As questões de gênero na construção contemporânea de Aztlán começaram a ser questionadas nos anos 1940, quando a vertente nacionalista do movimento chicano já as desqualificava como ameaça à coesão nacional. ${ }^{18}$ A partir dos anos 60 , com o fortalecimento do feminismo, essa desqualificação se tornou mais incisiva nas acusações de que as chicanas promoviam o faccionalismo no interior do movimento e assim 'traíam' os homens representantes da nação. ${ }^{19}$ Desafiadas a confrontar tanto o racismo no interior do feminismo hegemônico quanto a misoginia e homofobia no interior do movimento chicano, muitas chicanas feministas se articularam em torno da apropriação simbólica de Aztlán como lugar de enunciação crítica na intersecção de classe, raça, gênero e sexualidade. Ressaltando que o masculinismo era a base histórica da dominação asteca sobre outros povos indígenas, Gloria Anzaldúa argumentou que Aztlán deveria então ser compreendida como um projeto de reinterpretação histórica, e não como um retorno a valores patriarcais idealizados em nome de um discurso de origens. ${ }^{20}$

A partir dos anos 70, artivistas identificadas com o projeto político de Aztlán criaram intervenções denunciando a lógica do nacionalismo chicano e sua exclusão de mulheres da construção do imaginário coletivo. O movimento das chicanas muralistas teve bastante repercussão nesse sentido, já que seu olhar revisionário confrontou diretamente os episódios misóginos da Renascença Muralista no México, os quais haviam estabelecido também no movimento chicano a imagem do muralismo como uma arte eminentemente masculina. A arte muralista chicana, além de finalmente revisar essa narrativa a partir dos anos 70 , também destronou o muralismo centrado em figuras autorais e passou a engajar o imaginário mítico de Aztlán com questões específicas à história e ao cotidiano das comunidades chicanas. Passou, por exemplo, a aliar as periferias urbanas, nas quais as comunidades indígenas vinham sendo segregadas, às áreas rurais, das quais vinham sendo expulsas. Nesse sentido, a partir dos anos 70 , tiveram grande impacto os murais das chicanas Judy Baca, Alma López, Juana Alícia, Yreina Cervántez, e o coletivo Mujeres Muralistas, entre outras. ${ }^{21}$

Marcando a presença das latinas e chicanas na trajetória histórica de Aztlán, um mural representativo da apropriação do espaço patriarcal do muralismo chicano é a colagem digital Las Four de Alma López (1997), instalada no projeto habitacional Estrada

\footnotetext{
${ }^{14}$ Néstor García CANCLINI, 2008, p. 16.

${ }^{15}$ Antonio CAMEJO, 1971. Veja também Rodolfo ACUÑA, 1988.

${ }^{16}$ GÓMEZ-PEÑA, 1991 , p. 56.

${ }^{17}$ Essa crítica se desenvolve pelo menos desde José MARTí, 1939 e Roberto Fernández RETAMAR, 1995.

${ }^{18}$ Daniel ALARCÓN, Caren KAPLAN e Minoo MOALLEM, 1999.

${ }^{19}$ Denise SEGURA e Beatriz M. PESQUERA, 1988-1990, p. 72-75.

20 Gloria ANZALDÚA, 2005, p. 22; Michael HAMES-GARCIA, 2000.

${ }^{21}$ Compunham o coletivo Mujeres Muralistas Patricia Rodríguez, Irene Pérez, Graciela Carrillo e Consuelo Méndez. Veja Guisela LATORRE, 2008b.
}

194 Estudos Feministas, Florianópolis, 23(1): 191-206, janeiro-abril/2015 
Courts, Los Angeles/CA, uma área emblemática dos muralistas chicanos dos anos $70 .{ }^{22}$ Las Four subverteu a iconografia masculinista de um dos murais famosos do local, Los Cuatro Grandes de Ernesto de la Loza (1993), que faz homenagem aos grandes ícones da fraternidade entre chicanos e mexicanos (conhecida por carnalismo): César Chavez, Emiliano Zapata, Francisco Villa e Mario Moreno Cantinflas. Paralelamente a essa iconografia, López e suas assistentes Patricia Ramirez e Christian Gorocica digitalizaram a imagem de quatro mulheres jovens da comunidade. A importância histórica dessas quatro é sugerida pela imagem sobreposta de quatro latinas de gerações anteriores, cuja relevância na história de Aztlán ainda é ofuscada pela iconografia masculinista: Dolores Huerta, cofundadora, com César Chaves, do Sindicato de Trabalhadores Agrícolas da América; Sor Juana Inés de la Cruz, escritora, filósofa e freira mexicana do século XVII; uma soldada anônima, representando as mulheres que lutaram na Revolução Mexicana de 1910 ao lado de soldados reconhecidos, como Zapata e Villa; e Rigoberta Menchú, a escritora e ativista maia que recebeu o Prêmio Nobel da Paz por sua luta contra a intervenção militar dos Estados Unidos na Guatemala e pelos direitos dos povos indígenas. ${ }^{23}$ No terceiro plano ao fundo, López insere a imagem icônica da pedra de Coyolxauhqui, na qual foi esculpido o corpo desmembrado da deusa asteca da lua. ${ }^{24} \mathrm{Se}$, na narrativa asteca, o assassinato de Coyolxauhqui por seu irmão, deus da guerra, inaugura o domínio patriarcal, a imagem da pedra indígena digitalizada no plano ao fundo e ao alto do mural não reflete meramente uma nostalgia de origens (por meio do resgate estético do passado), nem uma nostalgia pós-moderna abstrata (na qual uma narrativa histórica de estilos estéticos substitui uma suposta 'história real') ${ }^{25}$ Ao contrário, a inserção da historiografia indígena no mural ressalta que as relações suprimidas com o passado permanecem dinâmicas e que sua memória é intervencionista, pois potencializa uma crítica contundente do presente para poder reconstituir, contra a amnésia histórica, a consciência da violência de gênero e temporalidade em contextos interligados da colonialidade do poder. ${ }^{26}$

As releituras de Aztlán a partir dos anos 90 vêm confrontando os mecanismos de controle de gênero e também de sexualidade no imaginário coletivo. Nas palavras de Cherríe Moraga,

Quando El Plan Espiritual de Aztlán foi concebido na geração passada, lésbicas e gays não eram visualizados como membros da 'casa'; nós não éramos reconhecidas como as irmãs plantando as sementes, o irmão fazendo a colheita. Não éramos contadas entre os membros do 'continente de bronze'. ${ }^{27}$

Essa crítica ressalta que os corpos são controlados por modos de pertencimento ancorados no sistema heterárquico da colonialidade do poder. Em contraste com hierarquia, heterarquia é definida como o entrelaçamento de vários comandos entre si de modo a ativarem-se uns aos outros, ciclicamente. ${ }^{28}$

${ }^{22}$ Visando promover o muralismo e artivismo comunitário entre jovens, López participou das atividades do centro SPARC (Los Angeles) como artista-em-residência, inclusive como colaboradora junto à professora e artivista Judy Baca (UCLA).

${ }^{23}$ Alma LÓPEZ, 1999, p. 80-81.

${ }^{24}$ A escultura em pedra Coyolxauhqui data de 1519 e encontra-se no Templo Mayor, Ciudad de Mexico.

Ressalto sua importância para a arte chicana, que há anos vem confrontando o femicídio em Juárez.

${ }^{25}$ Sobre essas categorias, veja Fredric JAMESON, 1991, p. 66-67.

${ }^{26}$ Sobre essa concepção de história, veja, por exemplo, Michel-Rolph TROUILLOT, 1995, e José Esteban MUÑOZ, 2009. Vale ressaltar que Las Four foi vandalizado por rapazes que declararam que as artistas deveriam ter escolhido "meninas melhores" (Kathleen Fizcallagan JONES, 2011, p. 64), ou seja, que não tinham que ser mulheres de cor autoempoderadas (Ricardo F. PÉREZ, 2013, p. 191).

27 Cherríe MORAGA, 1993, p. 159. 
Ampliando esse conceito para o de amálgama, na qual as fronteiras entre os vários 'comandos' ou eixos hierárquicos é indiscernível, ${ }^{29}$ Elizabeth Freeman comenta:

Deslocar o tempo (d)e sua história significa reconhecer como as relações eróticas e os atos corporais que as sustentam funcionam como amálgamas das estruturas normativas que denominamos família e nação, gênero, raça, classe e identidade sexual; e esse reconhecimento se dá quando alteramos o tempo e o ritmo, quando remixamos a memória e o desejo, quando recapturamos o excesso.

Nesse contexto, a própria designação queer é esvaziada de seu poder contestatório a não ser que se faça irredutível (mas não isento) em relação às interpelações identitárias, passando a significar um lugar de enunciação crítica à crononormatividade e suas ressonâncias heterárquicas. Assim, o que emerge é não só uma visão da fronteira queer como também uma visão queer da fronteira. Este é um chão do qual se desalinha a aparente naturalidade das relações diretas (straight) já instaladas entre os significados e significantes das temporalidades atravessadas em Aztlán, como se fossem fixos, e entre signos e contextos, como se fossem controláveis. ${ }^{31}$

\section{Guadalupe, a mestiça clborgue de Marion Martinez}

Em sua reconstituição da imagem da serpente na cosmologia chicana, Gloria Anzaldúa se refere à reconfiguração de Guadalupe, símbolo psicológico, político e espiritual da cultura chicana, lembrando que ela é inseparável da deusa pré-asteca Coatlalopeuh, cujo poder foi destituído pelo masculinismo asteca. Sob o regime crononormativo colonial e católico, os aspectos mais densos e complexos de Coatlalopeuh foram projetados na figura de Coatlicue, expulsa ao submundo. Para reduzir ainda mais a complexidade de Coatlalopeuh, a hegemonia asteca buscou substituí-la por um símbolo de pureza moral, a figura de Tonantzi, abraçada pela igreja católica. Assim, Guadalupe-Tonantzi foi dessexualizada e transformada na mãe abnegada e padroeira redentora da nação mexicana, a Virgem de Guadalupe. ${ }^{32}$

Subvertendo essa imagem crononormativa que narra a nação latina como um processo de purificação eurocêntrica, branca e submissa, as artistas chicanas feministas

\footnotetext{
${ }^{28}$ Veja Douglas R. HOFSTADER, 1999 [1979], p. 134.

${ }^{29}$ Ressalto que, mesmo sendo indiscerníveis essas fronteiras, o fato de serem codificadas culturalmente como "comandos" ou eixos hierárquicos distintos as insere também no âmbito da hierarquia e heterarquia. Aqui sigo o argumento do realismo pós-positivista

elaborado, por exemplo, em Paula M. L. MOYA e Michael R. HAMES-GARCIA, 2000.

${ }^{30}$ FREEMAN, 2010 , p. 172.

${ }^{31}$ Utilizo o termo queer apesar de suas limitações, das quais destaco aqui apenas a de que vem sendo cooptado de modo a não mais engajar a diferença racial e de classe. Por isso mesmo, é necessário manter vivo seu epistema descolonial, na contramão de seu trânsito teórico do contexto da teorização chicana para o contexto da teoria anglo-americana, nos anos 90, para retomá-lo também na contramão de seu trânsito teórico do contexto anglo-americano para o latino-americano mais amplo, a partir dos anos 2000 . Em sua concepção chicana descolonial, o termo queer nomeia coalizões entre pessoas de afiliações identitárias distintas marcadas pela exclusão, com a sexualidade como referência. Veja ANZALDÚA, 2005 [1987] e 1991. Para outras leituras do uso do termo em contextos latino-americanos, veja, por exemplo, María Amelia VITERI, José Fernando SERRANO e Salvador VIDAL-ORTIZ, 2011, e Richard MISKOLCI, 2014.

${ }^{32}$ ANZALDÚA, 1987, p. 29-40. O significado contemporâneo de Guadalupe é inseparável também da figura de Malintzin, ou La Malinche, condenada como símbolo da sexualidade feminina traidora da nação: "O imperativo nacionalista é retornar ao passado, como numa regressão, um retorno à mãe, mas a mãe não pode ser Malinche. Ela deve ser La Virgen de Guadalupe; não pode ser sexual. [...] Daí, o nacionalismo se torna um retorno à mãe - Aztlán - onde a mulher só pode ser metáfora e objeto" (Emma PÉREZ, 1999, p. 122).
} 
se reapropriam da imagem de Guadalupe e realçam seu potencial contestatório como símbolo da força ambígua, híbrida, resistente e criativa no interior da própria opressão. ${ }^{33}$

A imagem anacronista de Guadalupe foi contestada na exposição Cyber-Arte: Tradition Meets Technology (2001), cujo objetivo curatorial explícito foi "fundir elementos tradicionalmente definidos como 'folclóricos' com tecnologia computacional de ponta". ${ }^{34}$ Caracterizando "elementos folclóricos" como sendo "tradicionalmente definidos" por sua suposta incompatibilidade com a tecnologia, essa descrição curatorial do evento já ressalta a arbitrariedade do discurso crononormativo e encena efetivamente que não é o folclórico, mas sim sua definição convencional e dicotômica, que é ultrapassada. Como nos lembra Ramírez, referindo-se aos termos de Lucy Lippard, o conceito de arte folclórica como aquela que meramente reflete o meio ambiente ignora que este nunca é isolado do contexto sociocultural no qual a arte se insere. ${ }^{35}$ É somente por reduzir o folclórico ao pré-social que se pode explorá-lo como uma extração colonizadora do passado, assim comodificado. Por isso, o uso do termo tradicional no subtítulo da exposição pode engajar o projeto descolonial da curadoria se for compreendido não no sentido dominante de uma temporalidade ultrapassada, ou uma condição invariante em oposição ao dinamismo contemporâneo, mas, ao contrário, enquanto contemporaneidade relacional que incorpora o dinamismo de significados históricos de modo que não possam ser contidos, nem imobilizados no tempo. Nesse sentido, tradição se refere à tradução cultural incessante pela qual se atualizam conteúdos epistêmicos resistentes à assimilação crononormativa. ${ }^{36}$ No contexto em que se realizou a exposição Cyber-Arte, esta distinção conceitual é significativa porque aponta para o anacronismo lucrativo que congela o dinamismo da tradição nesta outra fronteira palimpséstica da América Latina: o estado de New Mexico, fronteira entre o império espanhol e a República Mexicana no século XIX. ${ }^{37}$ Apesar de seus altíssimos índices de violência socioambiental, esse estado denominado 'Novo México' ainda é construído discursivamente como um local de beleza natural inesgotável, uma terra bucólica, remota no espaço e no tempo. ${ }^{38}$ Essa imagem pastoral é propagada pela indústria do turismo e da especulação imobiliária, que dependem de suprimir as marcas da contemporaneidade dos povos da região (fictícia?) de Aztlán enquanto esta serve de repositório de refugo radioativo e fonte de mão de obra sub-remunerada. ${ }^{39}$

Uma das âncoras que sustentam o discurso bucólico sobre o Novo México - e também sua repolitização - é a arte da santeria, ou escultura de santas/os em oratórios expostos em museus, bem como em estabelecimentos comerciais, que exercem pressão sobre as/os artistas para que produzam peças tipicamente rústicas de modo que possam confirmar sua procedência remota, exótica e anacrônica. O que não é típico dessa prática artística é a figuração de santos ao lado de material residual da indústria da informática. Segundo Silvia Spitta, tais inovações na santeria são geralmente rejeitadas pelos comerciantes no estado, muitos dos quais migraram de regiões mais abastadas da costa Leste, a partir dos

\footnotetext{
${ }^{33}$ ANZALDÚA, 1987, p. 29-40.

${ }^{34}$ A citação é do matrial curatorial de divulgação, conforme aponta Catherine S. RAMíREZ (2004, p. 83, nota 1). A exposição foi realizada no Museu de Arte Folclórica Internacional (MOIFA), em Santa Fé, no estado do Novo México, EUA, sob a curadoria de Tey Marianna Nunn. Incluiu obras de Marion Martinez, Alma López, Teresa Archuleta-Sagel e Elena Baca.

${ }^{35}$ Lucy LIPPARD, 1990, p. 77, citada por RAMíREZ, 2004.

${ }^{36}$ Refiro-me às concepções descoloniais de tradição e tradução cultural em GILROY, 1993, p. 101, e Gayatri Chakravorty SPIVAK, 2005 [2000], respectivamente.

37 Sobre Aztlán como palimpsesto, veja Daniel ALARCÓN, 1997.

${ }^{38}$ Laura PULIDO, 1996, p. 35-36, citada por RAMÍREZ, 2004.

${ }^{39}$ Sylvia RODRÍGUEZ, 1996, citada por RAMÍREZ, 2004.
} 
anos 20, para investir no comércio turístico do Novo México: desde os anos 20, os patrocinadores e clientes "tentam controlar e, ao que parece, até congelar no passado os trabalhos de artistas hispânicos e indígenas. [...] [E]ssas forças mercadológicas interferem nas práticas tradicionais de criação e inovação, forçando a reprodução incessante de formas coloniais (e anacronistas)". 40

Além de engessar o trabalho de muitas/os artistas, essa performatividade anacronista ainda reforça imagens do atraso sociocultural, as quais naturalizam o barateamento da mão de obra nas indústrias high-tech da região.

Ao contrário das outras três artistas que se valeram de software digital para a elaboração de seus trabalhos expostos na coletiva Cyber-Arte: Tradition Meets Technology, Marion Martinez elaborou suas esculturas em hardware reciclado, sobrepondo placasmães, discos rígidos, chips, fiação e outros elementos residuais. ${ }^{41}$ Esses componentes enfatizam não só a materialidade invisibilizada pela tecnologia de ponta, como também a rapidez com que ela se torna residual e obsoleta, e só então também acessível às margens do capital - na proporção inversa da lentidão de sua decomposição de alto risco em regiões reiteradas sistematicamente como alvos de descarregamento residual. ${ }^{42}$ Afirmando, na esteira do afrofuturismo, uma concepção mais ampla de tecnologia para incluir seu resíduo também material, Martinez desestabiliza a fronteira que define high-tech e low-tech, problematizando a própria diferença entre a tecnologia e seu resíduo como uma exclusão performática, biopolítica e cronopolítica.

Em Oratorio a La Virgencita (ver Figura 1), Martinez elabora surpreendentemente a imbricação da aura tecnológica em seu resíduo excluído. ${ }^{43}$ Esculpida e montada em um oratório de madeira do século XIX, emoldurado por rosas que, na iconografia guadalupana, aludem ao real, e em Martinez também à sua produção histórica, a imagem de Guadalupe aqui emerge delineada por camadas auráticas de placas e componentes condutores. Significativamente, esses materiais configuram apenas o rosto, a roupa e a aura, deixando entreaberto, no lugar do corpo, um espaço oco e transparente do qual Guadalupe aparenta transcender sua própria construção. Essa aparência não se sustenta, porém, porque os materiais residuais que delimitam o espaço vazio (assim como as rosas delimitam o próprio interior do oratório) também lembram, como vestígios, as relações socioculturais suprimidas na diluição do concreto no etéreo e do opaco no transparente. Nesse contexto, o Oratorio a La Virgencita é uma metanarrativa do mito da transcendência tecnológica, uma metanarrativa da suposta imaterialidade da tecnologia, inclusive religiosa - e uma dessacralização tanto de Guadalupe quanto da tecnologia que ela passa a incorporar.

Mesclando elementos históricos do passado e do presente, codificados por materiais antigos ou familiares à tradição santeira, de um lado, e materiais residuais da indústria da computação, de outro, Martinez ressignifica o resíduo tecnológico como um dispositivo cronopolítico familiar à região do Novo México, onde ela nasceu e cresceu. ${ }^{44} \mathrm{Em}$ Los Luceros, uma comunidade rural a aproximadamente $70 \mathrm{~km}$ do laboratório de Los Alamos (LANL), cerca de 500 mil metros cúbicos de lixo tóxico radioativo vêm sendo armazenados desde 1944, de acordo com o grupo ativista Los Alamos Study Group, com alto risco para a população local

40 Silvia SPITTA, 2009, p. 140.

${ }^{41} \mathrm{O}$ argumento crucial de que Martinez estende $\mathrm{O}$ afrofuturismo à arte chicanafuturista é central em RAMÍREZ, 2004.

42 RAMÍREZ, 2004, p. 68.

${ }^{43}$ A escultura de Martinez enfocada aqui é apenas uma das nove por ela expostas em Cyber-Arte: Tradition Meets Technology (2001).

${ }^{44}$ Martinez não se define como santeira; entretanto, suas intervenções artísticas a inserem na tradição santeira, como argumenta RAMÍREZ, 2004, p. 70. 
- cuja subsistência por vezes depende de se deslocar (por vezes após vender suas terras) para trabalhar no LANL (como fizeram Martinez, sua mãe e irmã). ${ }^{45}$

\section{Cronopolíticas cyborg/ ciborgue}

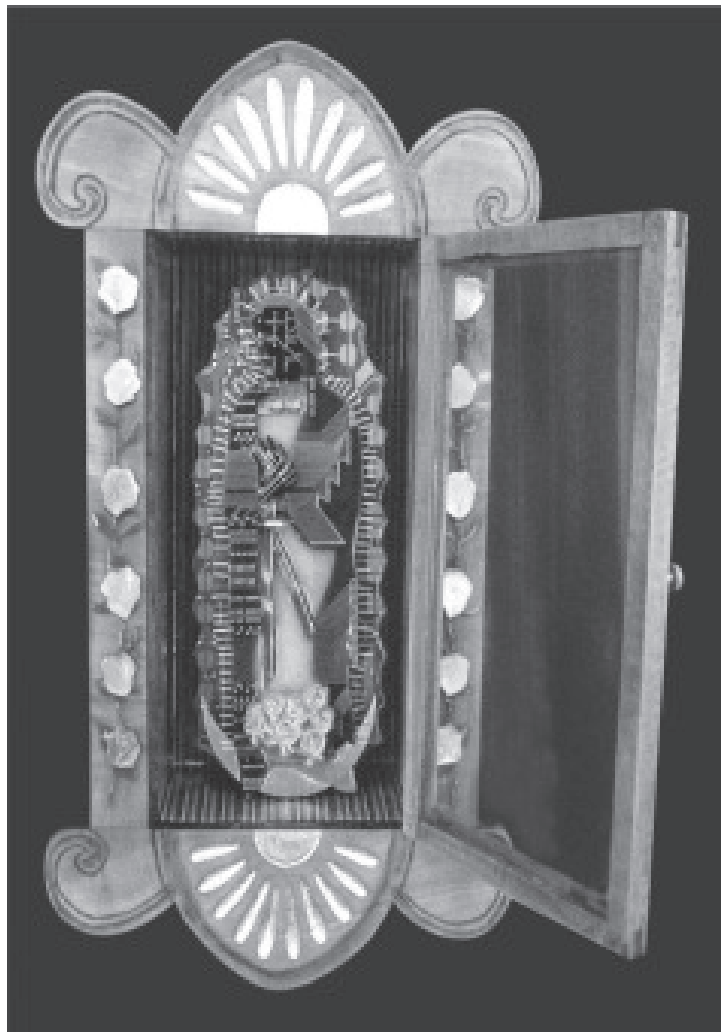

A inviabilidade da concepção purista de Guadalupe fica evidente na apropriação de sua imagem como protetora não só de quem se encontra do otro lado da fronteira com os EUA, mas também de quem se encontra do outro lado de sua fronteira mais difusa, a tecnológica. Difundindo-se virtualmente, como Guadalupe, a tecnologia digital é normalmente vista como uma essência imaterial capaz de transcender barreiras socioculturais. Essa "imaterialidade", porém, é mais precisamente a divisa entre quem conhece e quem ignora o custo de simular a transcendência pós-social. Nesta divisa, abre-se a fronteira, na concepção de Anzaldúa: "um lugar vago e indeterminado criado pelo resíduo emocional de uma divisa arbitrária". ${ }^{47}$

Em seu estudo sobre o pensamento de Anzaldúa em relação à ficção científica, Catherine Ramírez

Figura 1 - Oratorio a la Virgencita (2000), de Marion C. Martinez. Instalação de parede em madeira e placas condutoras de circuitos eletrônicos $(50,8 \mathrm{~cm}$ x 30,5cm x 10,2 cm). Imagem digitalizada. Cortesia da artista. traça uma analogia explícita entre a ciborgue de Donna Haraway e a nova mestiça de Anzaldúa, ressaltando que ambas interrogam a estabilidade de categorias sociais para viabilizar construções coalizionárias entre perspectivas distintas. ${ }^{48}$

Chela Sandoval também aponta que, enquanto sujeito subalterno, a nova mestiça é sempre já ciborgue porque ela conhece bem "a dor da imersão do tecido de seu próprio organismo com a máquina bem como as condições robóticas $e$, ao final do século $X X$, as

\footnotetext{
${ }^{45}$ RAMÍREZ, 2004, p. 66-69. A informação sobre o resíduo tóxico do LANL foi divulgada pelo site da organização não governamental Los Alamos Study Group. Veja http://www.lasg.org/waste.htm.

${ }^{46}$ Utilizo as grafias distintas, cyborg e ciborgue, para discernir entre posicionamentos epistêmicos incompatíveis (crononormativas e descoloniais, respectivamente).

${ }^{47}$ ANZALDÚA, 1987, p. 3.

${ }^{48}$ Catherine RAMíREZ, 2002, p. 385. Sobre a concepção e o contexto feminista da nova mestiça, veja Cláudia de Lima COSTA e Eliana de Souza ÁVILA, 2005.
} 
condições ciborguianas sob as quais a noção de agência humana necessariamente adquire novos significados". ${ }^{49}$

Como toda analogia, contudo, esta também discerne não só semelhanças como também diferenças. Rosi Braidotti sublinha:

Cyborgs, no sentido de corpos tecnologicamente mediados, incluem não só os corpos high-tech dos pilotos de combate, ou dos ícones culturais de Hollywood, mas também as massas anônimas de corpos explorados e sub-remunerados, em sua maioria mulheres e crianças em fábricas multinacionais e naqueles bolsões de mão-de-obra subremunerada no interior das economias avançadas alimentando a economia global centrada na tecnologia. ${ }^{50}$

A distinção não é categórica, entre high tech e low tech (já que a colonialidade do poder abarca ambas), mas entre perspectivas crononormativas, de um lado, e descoloniais, de outro. Anzaldúa parece já ter antecipado a resiliência necessária a essa distinção em 1987, quando definiu a nova mestiça como agente de uma identidade não só antiessencialista como também, e crucialmente, epistêmica: "un amasamiento[,] um ato de juntar e unir que não apenas produz uma criatura tanto da luz como da escuridão, mas também uma criatura que questiona as definições de luz e de escuro e lhes dá novos significados." ${ }^{51}$ Em contraste, o cyborg pós-social, mesmo emergindo de uma identidade antiessencialista, ainda ocupa um lugar desinteressado em "questiona[r] as definições de luz e de escuro e lhes da[r] novos significados". Em outras palavras, o cyborg ainda ocupa um lugar epistêmico supostamente genérico, alheio aos conhecimentos específicos de sistemas simbólicos fundados no escrutínio da colonialidade do poder eurocêntrico.

Atenta a essa distinção necessária, numa das entrevistas sobre seu famoso ensaio, Manifesto Ciborgue (1985), ${ }^{52}$ Haraway teve que enfatizar que a ciborgue não é uma figura imperializante, mas sim

[...] uma figura numa família de figuras deslocadas [...], o que permite sua conexão com outras pessoas não-originais (ciborgues são pessoas não-originais) multiplamente deslocadas. Poderia haver uma família de figuras populando nossa imaginação desses mundos pós-coloniais e pós-modernos que não fossem tão imperializantes em termos de uma figuração singular, monolítica, da identidade?

Assim, apenas cinco anos após a primeira publicação de seu manifesto (período esse em que se iniciou uma verdadeira explosão de vozes sobre a ciborguização e sua relação com outros processos de hibridização), Haraway já percebia o potencial imperializante de sua frase "somos todos/as ciborgues" - em vias de abstrair, elitizar e cooptar a ciborgue como sujeito soberano, pós-social, supostamente transcendendo a história. Na entrevista mencionada acima, Haraway argumentou que, se "somos todos/as ciborgues", como ela havia proposto em seu manifesto, corremos o risco de diluir nossas diferenças - ou melhor, de encobri-las. ${ }^{54}$ Alertou, então, contra a redução transcendentalista da ciborgue a uma narrativa escapista:

${ }^{49}$ Chela SANDOVAL, 1999, p. 48. Desde os anos 70, Guadalupe vem sendo reconfigurada nas intervenções artísticas chicanas como a nova mestiça, trabalhadora das classes média e baixa, inclusive como faxineira e costureira. Veja, por exemplo, os trabalhos de Ester Hernández, Yolanda López e Amalia Mesa-Bains em Arturo J. ALDAMA e Naomi H. QUIÑONEZ, 2002; Laura E. PÉREZ, 2007; Silvia SPITTA, 2009, entre outros. Sobre reconfigurações lésbicas de Guadalupe, veja Luz CALVO, 2004 e Maurício de BRAGANÇA, 2008.

${ }^{50}$ Rosi BRAIDOTTI, 2006, p. 30.

${ }^{51}$ ANZALDÚA, 2005 [1987], p. 708, grifo no original.

${ }^{52} \mathrm{O}$ manifesto foi publicado primeiramente em $1985 \mathrm{sob}$ o título que aqui traduzo por Manifesto pró-ciborgue (1985) e depois editado e republicado em 1991. As traduções brasileiras são de 1994 e 2009.

${ }^{53}$ Constance PENLEY, Andrew ROSS e Donna HARAWAY, 1990, p. 17-18, grifo no original.

${ }^{54}$ Sobre este argumento, veja também Paula M. L. MOYA, 2000b [1997]; RAMÍREZ, 2002; e BASTIAN, 2006. 
Qualquer estratégia transcendentalista é mortífera: produz a morte, por meio do medo da morte. Essas jogadas holísticas, transcendentalistas, prometem um jeito de escapar da história, de se fazer de Deus. Um jeito de negar a mortalidade. ${ }^{55}$

Dessa perspectiva, o cyborg como sujeito transcendente ou pós-social não passa de uma "suposta descolonização" ${ }^{56}$ que tende a (re)colonizar a nova mestiça como sujeito obsoleto porque 'ainda social'. Em contraste, o argumento de Haraway é que o cyborg é um "terreno de contestação" onde narrativas futuristas vêm sendo reduzidas a "celebrações tecnofascistas da invulnerabilidade" ou, ao contrário, demonizadas em defesa de uma suposta pureza "contrarracional". Em tal terreno instável não há garantias, evidentemente, mas isso não significa que se deva "desistir do jogo" - mesmo que as regras sejam desiguais:

É inteiramente possível, até provável, que as pessoas que querem transformar as imagens e as realidades sociais dos cyborgs em terrenos mais contestados - onde as pessoas têm ideias diferentes sobre a configuração de suas vidas - vão perder, e já estão perdendo em todo o planeta.

No discurso pós-social criticado por Haraway, essas pessoas tendem a perder porque o acesso à tecnologia estende seu raio de recepção global, mas não o raio de impacto de conteúdos epistêmicos emitidos localmente em rede. Tal regime de equivocação permite afirmar sem constrangimento que, por exemplo, "[e]m sociedades altamente desenvolvidas e interligadas em rede [networked], como os EUA, a percepção [awareness] humana compreende a ponta de uma pirâmide imensa de fluxos de dados, a maioria dos quais ocorrem entre máquinas" ${ }^{58}$ Forjando esse discurso igualitário, N. Katherine Hayles propõe que nos distanciemos do sujeito liberal do humanismo (como se neutralizá-lo garantisse a democratização do conhecimento); porém, ela caracteriza tal distanciamento como um modo de corrigir a "ênfase exacerbada sobre a consciência [consciousness] para uma visão mais nítida da cognição que permeia a matéria corporal, estendendo-se ao meio-ambiente social e tecnológico". ${ }^{59}$ Nesse raciocínio, a extensão ao "meio ambiente social e tecnológico" é apenas de cima para baixo, ou seja, do alto da "ponta de uma pirâmide imensa de fluxos de dados." Evidentemente, estes não operam num vácuo socioeconômico, mas sim a partir de "sociedades altamente desenvolvidas" que propagam seus epistemas crononormativos por meio dos "fluxos de dados" já em circulação. Em outras palavras, os fluxos de dados é que constituem a expansão epistêmica das "sociedades altamente desenvolvidas e interligadas em rede, como os EUA". Esse looping monocêntrico reduz o conhecimento à cognição, venerando como avanço tecnológico a perpetuação da pirâmide, como que transcendendo os epistemas antes supostamente restritos ao paradigma da consciência para o paradigma da "visão mais nítida" da cognição. Nessa operação crononormativa, qualquer alteridade epistêmica que questione os conteúdos dos "fluxos de dados" não passa de uma obsoleta "consciência humana' cuja volição ainda interfere com a neutralidade da cognição, ali na ponta da pirâmide ocupada pelas "sociedades altamente desenvolvidas e interligadas em rede"!

Com efeito, a opressão opera por meio não só de atos explícitos de proibição como também ao constituir sujeitos, lugares e temporalidades abjetas - nem nomeadas, nem proibidas, dentro da economia da lei, mas simplesmente relegadas ao passado. ${ }^{60}$ Nesse regime, as divisas entre quem configura os recursos e quem os recebe já configurados (ou

${ }^{55}$ PENLEY, ROSS E HARAWAY, 1990, p. 20.

${ }^{56}$ Veja Gayatri Chakravorty SPIVAK, 2010 [1985], p. 67.

${ }^{57}$ PENLEY, ROSS E HARAWAY, 1990, p. 13

${ }^{58} \mathrm{~N}$. Katherine HAYLES, 2006, p. 161, grifos meus.

${ }^{59}$ HAYLES, 2006, p. 161, grifos meus.

${ }^{60}$ Mary Louise BUTLER, 1993. 
em estado residual) se ampliam crescentemente: enquanto algumas pessoas parecem transcender restrições territoriais, outras ficam imobilizadas, presas a territórios cada vez mais esvaziados de seus recursos naturais. ${ }^{61}$

Assim, a mestiça ciborgue, mesmo sendo irredutível a essa prescrição anacronista, tende a ser reiterada como objeto pré-transcendental à narrativa triunfalista que a (re)instala como sujeito anacrônico, reconstituindo-se sobre sua subalternidade. Mesmo a contemporaneidade da nova mestiça enquanto ciborgue tende a ser assim relegada ao passado, já que nela as marcas materiais da história são suprimidas e essencializadas como se fossem evidência de seu próprio atraso tecnológico. Chegamos então a um impasse, porque na ciborguização a nova mestiça tende a ser reiterada como objeto que meramente assimila os avanços da escala evolucionista, excluída no ato mesmo de sua suposta inclusão no momento tecnológico-civilizatório que definiria o pós-social.

Esse impasse se codifica na tensão necessária entre cyborg/ciborgue, no processo incessante de congelar/descongelar cada novo paradigma que venha a simular um ponto final à narrativa da história. Se o cyborg prevalece como narrativa positiva e tecnofílica sobre a nova mestiça, assim reduzida a narrativa negativa, tecnofóbica e anacrônica, é necessário tornar legíveis as novas ancoragens normalizantes que reduzem a ciborgue a uma metáfora universalizante, esvaziada de sua especificidade constituída sobre o lado anacronizado da fronteira tecnológica.

Tendo desmistificado a transparência tecnológica do cyborg, o espaço vazio no lugar esculturado do corpo de Guadalupe emerge com outros significados na ciberarte de Martinez. Apontando para a realidade social invisibilizada nessa fabricação do cyborg pós-social, o Oratorio a La Virgencita enfatiza a corpor(e)alidade de processos tais como hibridização, ambivalência, irresolução, etc., quando estes passam a ser utilizados para diluir conflitos sociais e epistemas descoloniais. Considerando que "invisibilidade é o nome da presença do subalterno para o grupo dominante",,2 faz sentido ler esse não-lugar corporal como o produto discursivo-material do anacronismo que invisibiliza a mestiça ciborgue à sombra do cyborg pós-social.

Dessa perspectiva, o altar de Oratorio a La Virgencita é palco de uma reapropriação: um meio de tornar pública a perspectiva de quem vê na imaterialidade não a transcendência dos problemas sociais, mas, ao contrário, o próprio efeito de suprimi-los sob o manto aurático que, como o de Guadalupe, precisa ser dessacralizado. Assim, a mestiça ciborgue de Martinez não só recusa a tecnofobia e o purismo autenticista como também critica a idealização do mero acesso à tecnologia como uma possibilidade de transcender assimetrias socioculturais, e instiga nossa percepção de que a crise cuja superação é tematizada pelo cyborg está longe de ser obsoleta.

A mobilidade do cyborg universalizado é celebrada às custas da invisibilidade daquelas cuja imobilidade é atribuída à anacronia que lhes é supostamente própria como se houvesse uma essência de incapacidade temporal de cruzar fronteiras para ingressar no espaço-tempo transnacional. Mesmo o discurso antiessencialista é reduzido, portanto, de modo a permitir ao imaginário dominante perpetuar o discurso colonial no ato aparentemente avançado de negar a diferença binária. Nesse contexto, em que até a desestabilização de binarismos é reconfigurada para o upgrade da colonialidade do poder, a recusa da linearidade temporal na ciberarte chicana traduz os resíduos tecnológicos como vestígios reais de futuros irredutíveis ao mapeamento crononormativo - ou seja, como guias de atenção ao que nem a arbitrariedade das regras do jogo consegue conter.

${ }^{61}$ Veja Zygmunt BAUMANN, 1998; HAYLES, 2006; e Joanna ZYLINKSKA, 2002.

${ }^{62}$ Mary Louise PRATT, 1992, p. 13. 


\section{Referências}

ACUÑA, Rodolfo. Occupied America: A History of Chicanos. New York: Harper Collins, 1988. AHMAD, Aijaz. "Teoria dos três mundos: fim de um debate". In: Linhagens do presente: ensaios. Tradução de Sandra Guardini T. Vasconcelos. São Paulo: Boitempo, 2002. p. 167-196.

ALARCÓN, Daniel. The Aztec Palimpsest: Mexico in the Modern Imagination. Tucson: University of Arixona Press, 1997.

ALARCÓN, Norma; KAPLAN, Caren; MOALLEM, Minoo (Ed.). Between Women and Nation: Nationalisms, Transnational Feminisms, and the State. Durham: Duke University Press, 1999.

ALDAMA, Arturo J.; QUIÑONEZ, Naomi H. (Ed.). Decolonial Voices: Chicana and Chicano Cultural Studies in the 21st Century. Bloomington: Indiana University Press, 2002.

ANZALDÚA, Gloria. Borderlands/La Frontera. San Francisco: Aunt Lute Books, 1987.

"La conciencia de la mestiza/rumo a uma nova consciência". Tradução de Ana Cecília Accioli Lima. Revistas Estudos Feministas, Florianópolis, v. 13, n. 3, p. 704-719, set.-dez. 2005 [1987].

. "To(0) Queer the Writer - Loca, escritora y chicana." In: WARLAND, Betsy, ed., InVersions: Writing by Dykes, Queers, and Lesbians. Vancouver: Press Gang, 1991. p. 249-63.

BASTIAN, Michelle. "Haraway's Lost Cyborg and the Possibilities of Transversalism." Signs: Journal of Women in Culture and Society, v. 31, n. 4, p. 1027-1049, 2006.

BAUMAN, Zygmunt. Globalization: The Human Consequences. New York: Columbia University Press, 1998.

BRAGANÇA, Maurício de. "Lupe Loves Sirena: imagens guadalupanas e discurso lésbico chicano na obra de Alma López." Cadernos de Letras da UFF, Niterói, n. 34, p. 207-224, 2008.

BRAIDOTTI, Rosi. Transpositions: On Nomadic Ethics. Cambridge and Malden: Polity Press, 2006. BUTLER, Judith. Bodies that Matter: On the Discursive Limits of Sex. New York: Routledge, 1993.

CALVO, Luz. "Art Comes for the Archbishop: The Semiotics of Contemporary Cicana Feminism and the Work of Alma López". Meridians, Northampton, v. 5, n. 1, p. 201-224, 2004.

CAMEJO, Antonio. Documents of the Chicano Struggle. New York: Pathfinder Press, 1971.

CANCLINI, Néstor García. Latino-americanos à procura de um lugar neste século. Tradução de Sérgio Molina. São Paulo: lluminuras, 2008.

COSTA, Cláudia de Lima; ÁVILA, Eliana de Souza. "Gloria Anzaldúa, a consciência mestiça e o 'feminismo da diferença'". Revista Estudos Feministas, Florianópolis, v. 13, n. 3, p. 691-703, set./dez. 2005.

COSTA, Cláudia de Lima. "Feminismo, tradução cultural e a descolonização do saber". Fragmentos, Florianópolis, v. 21, n. 2, p. 45-59, 2010.

DUSSEL, Enrique. 1492: O encobrimento do outro: a origem do mito da modernidade. Petrópolis: Vozes, 1993

EDELMAN, Lee. No Future: Queer Theory and the Death Drive. Durham and London: Duke Universtiy Press, 2004.

FREEMAN, Elizabeth. Time Binds: Queer Temporalities, Queer Histories. Durham: Duke University Press, 2010.

"Time Binds, or Erotohistoriography." Social Text, Durham, v. 23, n. 3-4 84-85, p. 57-68, Fall/Winter 2005.

GASPAR DE ALBA, Alícia; LÓPEZ, Alma (Ed.). Our Lady of Controversy: Alma López's Irreverent Apparition. Austin: University of Texas Press, 2011.

GILROY, Paul. The Black Atlantic: Modernity and Double-Consciousness. Cambridge: Harvard University Press, 1993.

GÓMEZ-PEÑA, Guillermo. "Border Brujo: A Performance Poem (From the Series 'Documented/ Undocumented')." The Drama Review, Cambridge, v. 35, n. 3, p. 48-66, Autumn 1991. 
HALBERSTAM, Judith. The Queer Art of Failure. Durham: Duke University Press, 2011.

HAMES-GARCIA, Michael. "How To Tell a Mestizo from an Enchirito: Colonialism and National Culture in the Borderlands." Diacritics, Baltimore, v. 30, n. 4, p. 102-122, 2000.

HARAWAY, Donna. "A Manifesto for Cyborgs: Science, Technology and Socialist Feminism in the 1980s." In: NICHOLSON, Linda N. (Ed.). Feminism and postmodernism. New York and London: Routledge, 1990 [1985]. p. 190-233.

HAYLES, N. Katherine. "Unfinished Work: From Cyborg to Cognisphere." Theory, Culture \& Society, London, v. 23, n. 7-8, p. 159-166, 2006.

HOFSTADER, Douglas R. Gödel, Escher, Bach: An Eternal Golden Braid. New York: Basic, 1999 [1979].

JAMESON, Fredric. Postmodernism, or, The Cultural Logic of Late Capitalism. Durham: Duke University Press, 1991.

JONES, Kathleen Fizcallagan. "The War of Roses: Guadalupe, Alma López, and Santa Fe." In: GASPAR DE ALBA, Alícia; LÓPEZ, Alma (Ed.). In: Our Lady of Controversy: Alma López's Irreverent Apparition. Austin: University of Texas Press, 201 1. p. 43-68.

LATORRE, Guisela. "Icons of Love and Devotion: Alma Lopez's Art”. Feminist Studies, College Park, v. 34, n. 1/2, p. 131-150, Spring/Summer 2008a.

Walls of Empowerment: Chicana/o Indigenist Murals of California. Austin: University of Texas Press, 2008b.

LIPPARD, Lucy. Mixed Blessings: New Art in a Multicultural America. New York: Pantheon Books, 1990.

LISBOA, Armando de Melo. "De América a Abya Yala - semiótica da descolonização". Revista Educação Pública, Cuiabá, v. 23, n. 53/2, p. 501-531, maio/ago. 2014.

LÓPEZ, Alma. Las Four. Mural digital, Estrada Courts, Los Angeles, CA, 1997. In: GASPAR DE ALBA, Alícia; LÓPEZ, Alma (Ed.). In: Our Lady of Controversy: Alma López's Irreverent Apparition. Austin: University of Texas Press, 2011 . p. 65. Imagem digitalizada.

"Maria de Los Angeles; Pre-Columbian and Post Conquest Goddesses; Qué Esconde La Esperanza? / What Is Hidden in Hope?" Frontiers: A Journal of Women Studies, v. 20, n. 1, p. 80-85, 1999.

LUGONES, María. "Heterosexualism and the Colonial/Modern Gender System." Hypatia, Baltimore, v. 22, n. 1, 186-209, 2007.

MALDONADO-TORRES, Nelson. "Enrique Dussel's Liberation Thought in the Decolonial Turn." Transmodernity: Journal of Peripheral Cultural Production of the Luso-Hispanic World, Merced, v. 1, n. 1, p. 1-31, 2011.

MARTÍ, José. Nuestra América. Buenos Aires: Editorial Losada, 1939.

MARTINEZ, Marion. Oratorio a La Virgencita. Instalação de parede em madeira e placas condutoras de circuitos eletrônicos (50,8cm x 30,5cm x 10,2 cm), 2000.

MARTINEZ, Theresa A. "The Double-Consciousness of DuBois and the 'Mestiza Consciousness' of Anzaldúa." Race, Gender, and Class, New Orleans, v. 9, n. 4, p. 158-176, 2002.

MCCLINTOCK, Anne. Imperial Leather: Race, Gender, and Sexuality in the Colonial Contest. New York and London: Routledge, 1995.

MIGNOLO, Walter. Histórias locais, projetos globais: colonialidade, saberes subalternos e pensamento liminar. Belo Horizonte: Editora UFMG, 2003 [2000].

MISKOLCI, Richard. "Um saber insurgente ao sul do Equador". Periodicus, Salvador, v. 1, n. 1, p. 1-25, maio/out. 2014.

MORAGA, Cherríe. "Queer Aztlán: The Re-Formation of Chicano Tribe." In: The Last Generation: Prose and Poetry. Boston: South End Press, 1993. p. 145-174.

MOYA, Paula M. L.; HAMES-GARCIA, Michael R. (Eds.). Reclaiming Identity: Realist Theory and the Predicament of Postmodernism. Berkeley: University of California Press, 2000 a. 
MOYA, Paula M. L. "Postmodernism, 'Realism,' and the Politics of Identity: Cherríe Moraga and Chicana Feminism." In: MOYA, Paula M. L.; HAMES-GARCIA, Michael R. Reclaiming Identity: Realist Theory and the Predicament of Postmodernism. Berkeley: University of California Press, 2000b [1997]. p. 67-101.

MUÑOZ, José Esteban. Cruising Utopia: The Then and There of Queer Futurity. New York and London: New York University Press, 2009.

.'Memory Performance: Luis Alfaro's 'Cuerpo Politizado'. In: Corpus Delecti: Performance Art of the Americas. London and New York: Routledge, 2000. p. 97-113.

PENLEY, Constance; ROSS, Andrew; HARAWAY, Donna. "Cyborgs at Large: Interview with Donna Haraway". Social Text, Durham, v. 25, n. 26, p. 8-23, 1990.

PÉREZ, Emma. The Decolonial Imaginary: Writing Chicanas into History. Bloomington: Indiana University Press, 1999.

PÉREZ, Laura E. Chicana Art: The Politics of Spiritul and Aesthetic Altarities. Durham: Duke University Press, 2007.

PÉREZ, Ricardo F. Vivancos. Radical Chicana Poetics. New York: Palgrave Macmillan, 2013.

PORTO-GONÇALVES, Carlos Walter. "Entre América e Abya Yala - tensões de territorialidades". Desenvolvimento e Meio Ambiente, Curitiba, n. 20, p. 25-30, jul./dez. 2009.

PRATT, Mary Louise. Imperial Eyes: Travel Writing and Transculturation. London: Routledge, 1992.

PULIDO, Laura. Environmentalism and Economic Justice: Two Chicano Struggles in the Southwest. Tucson: University of Arizona Press, 1996.

QUIJANO, Aníbal. "Colonialidade, poder, globalização e democracia". Novos Rumos, Marília, ano 17, n. 37, p. 4-28, 2002.

RAMÍREZ, Catherine. "Cyborg Feminism: The Science Fiction of Octavia E. Butler and Gloria Anzaldúa". In: FLANAGAN, Mary; BOOTH, Austin. Reload: Rethinking Women + Cyberculture. Boston: Massachusetts Institute of Technology, 2002. p. 372-402.

"Deus ex Machina: Tradition, Technology, and the Chicanafuturist Art of Martion C. Martinez". Aztlán, Oakland, v. 29, n. 2, p. 55-92, Fall 2004.

RETAMAR, Roberto Fernández. Caliban and Other Essays. Translated by E. Baker. Minneapolis: University of Minnesota Press, 1995

RODRÍGUEZ, Sylvia. The Matachines Dance: Ritual Symbolism and Interethnic Relations in the Upper Río Grande Valley. Albuquerque: University of New Mexico Press, 1996.

SANDOVAL, Chela. "Women Prefer a Choice". In: WOLMARK, Jenny (Ed.). Cybersexualities. Edinburgh: Edinburgh University Press, 1999.

SEGURA, Denise A.; PESQUERA, Beatriz M. "Beyond Indifference and Antipathy: The Chicana Movement and Chicana Feminist Discourse." Aztlán, Oakland, v. 19, n. 2, p. 69-92, Fall 1988-1990.

SPITTA, Silvia. Misplaced Objects: Migrating Collections and Recollections in Europe and the Americas. Austin: University of Texas Press, 2009.

SPIVAK, Gayatri Chakravorty. Pode o subalterno falar? Tradução de Sandra Regina Goulart Almeida, Marcos Pereira Feitosa e André Pereira Feitosa. Belo Horizonte: Editora UFMG, 2010 [1985].

"Tradução como cultura". Tradução de Eliana Ávila e Liane Schneider. Ilha do Desterro, Florianópolis, n. 48, p. 41-64, 2005 [2000].

TROUILLOT, Michel-Rolph. Silencing the Past: Power and the Production of History. Boston: Beacon Press, 1995.

VITERI, María Amelia; SERRANO, José Fernando; VIDAL-ORTIZ, Salvador. "Como se piensa lo 'queer' en América Latina?" Íconos, Quito, v. 15, n. 1, p. 47-60, enero 2011. 
WALSH, Catherine. "Shifting the Geopolitics of Knowledge: Decolonial Thought and Cultural Studies 'Others' in the Andes." Cultural Studies 21.2-3, p. 224-239, 2007.

ZYLINKSKA, Joanna (Ed.). The Cyborg Experiments: The Extensions of the Body in the Media Age. London: Continuum, 2002.

[Recebido em outubro de 2014 e aceito para publicação em novembro de 2014]

"From high-tech to Aztec": Chronoqueer Decolonization in Feminist Chicana Art Abstract: This article contextualizes chicana cyberart in the decolonial conception of the region of Aztlán, confirming clearly that "Latin America is not entirely in the territory which carries its name" (CANCLINI, 2008). This 'territorial' appropriation is also temporal: it is performative of decolonial temporality as it dethrones the colonialist regime of chrononormativity which disqualifies non-eurocentric epistemes by mapping them onto the past. Specifically, the article addresses how chicana cyberart decolonizes temporality by refusing the transcendentalist or post-social version of the cyborg narrative. Discussing specific ways in which chicana cyberart queers the chrononormative prescription of the future as high technology over the past as its low-tech residue, the article affirms Afrofuturism's broader conception of technology (which acknowledges its residue as its own suppressed supplement) as an effective threat to the chronic biopolitics of straight temporality.

Keywords: Decolonial art; Queer; Chrononormativity; Cyborg; Chicana Cyberart. 